\title{
AN APPROACH TO FUTURE HOSPITAL PLANNING IN ENGLAND
}

\author{
By Alner W. Hall, F.R.I.B.A.
}

We have asked Mr. Alner W. Hall, F.R.I.B.A., a leading Hospital Architect, to give his views on Hospital Planning. We record that Mr. Hall holds the appointment of Architect to the Royal College of Surgeons, the Middlesex Hospital, Guy's Hospital and St. Mary's Hospital and many others. We hope to present in later issues the views held by those who have to work in hospitals and their suggestions for improvement-EDITOR.

To satisfy the urgent need in this country for an increase in hospital bed-capacity and to bring the hospitals up to the requisite standard as compared with modern hospitals of a similar size on the Continent, it is clear that within a very short space of time large-scale building operations will have to be undertaken. Comparisons between our hospitals and the latest hospitals in Sweden and Switzerland, France and elsewhere, go to show that in many respects we lag behind these countries in the provision of sufficient and efficient accommodation for all the multifarious departments called for in a modern hospital. These great continental hospitals have been conceived and executed on a scale and with a thoroughness in detail of construction and equipment greatly to be admired. Clearly the knowledge gained from a study of their plans should, with advantage, be used where applicable when working out the designs for similar buildings in this country. Certainly it will be very necessary to have a clear indication from the appropriate authorities (presumably the newly-constituted Regional Boards) of the lines on which our new hospital buildings should be developed, but this should not mean the handing out of preconceived blueprints for building them, regardless of whether such plans will fit any particular site or not; this indeed would be disastrous and would ruin the chances of progress in design, construction and equipment.
The first thing that must be decided is the actual size of any particular hospital, and by size it is not meant merely the bed-caracity, although that is most important, but anso the size, number and scope of the various specialist departments which must be included in the hospital services. Then again the question of site and its size, shape and position in the area to be selected for the buildings must have very careful consideration, as, in the past, one of the greatest mistakes has been to select sites far too small, which has meant endless difficulties when the inevitable question of extensions has come up for discussion. It is therefore a matter of prime importance that any site selected must be of sufficient size and of the right shape for all present purposes, with considerable margin for future development Such sites are often difficult to find, especially in crowded districts and it may be that com= pulsory acquisition of the necessary space will be the only way by which to obtain the acreage required. In this article, except by way of comparison, it is not proposed to discuss the planning, extension or rebuilding of the great teaching hospitals in London or elsewhere, but rather to concentrate on outlining the approach to the planning of the district hospital as envisaged in the Hospital Survey. With regard, however, to the teaching hospitals in London, some at least are clearly indicated as having to 'stay put,' either on their present sites, or having by acquisition obtained additional land to extend or rebuild ; others are due to be moved out from the centre and will be rebuilt completely as selfcontained entities.

All these hospitals, whose primary function will be the teaching of medical students, will have some 1,000 or more beds, with medical schools attached and will require every requisite necessary to fit them for their great purpose. 
For the district hospitals, whose primary object will be the treatment of the sick, with, as a secondary object, facilities for post graduate teaching of general practitioners, the conditions will be different, not so much in size, planning or detail, but in their functions.

It is the future planning of these district hospitals that it is proposed now to discuss, and an endeavour will be made to show the lines upon which they may be developed.

It must be assumed that the site problem has $\mathrm{l}$;en solved and that the site selected, after consultation with the architect chosen to prepare the plans, is in every way satisfactory. With this point settled the next problem is to determine the final bed capacity. This clearly must-have some definite relation to the needs of the district and area to be served and is likely to range between 800 and 1,000 beds. Then follows the division of the agreed total into the various categories of medical, surgical and specialist cases, with a further sub-division to give the correct proportions between men, women and children.

Here is a suggested schedule of bed capacity, the proportions between the sexes, where applicable, being approximately equal :

SUGGESTED BED CAPACITY, ON THE BASIS OF A 25-BED SISTER'S UNIT

$\begin{array}{lllllll}\text { (a) Medical . } & \ldots & \ldots & \ldots & 8 / 25 & \ldots & 200\end{array}$

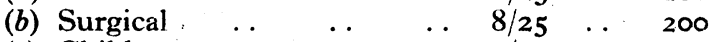

$\begin{array}{lllllll}\text { (c) Children } & \ldots & \ldots & \ldots & 3 / 25 & \ldots & 75\end{array}$

$\begin{array}{llllll}\text { (d) Gynaecological } & \ldots & \ldots & 2 / 25 & \ldots & 50\end{array}$

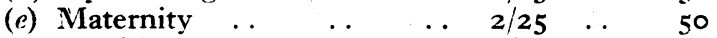

$\begin{array}{lllllll}\text { (f) E.N.T. } & \ldots & \ldots & \ldots & 2 / 25 & \ldots & 50\end{array}$

(g) Fracture and Orthopaedic .. $2 / 25 \quad \ldots \quad 50$

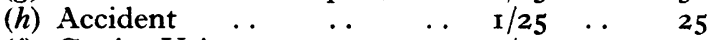

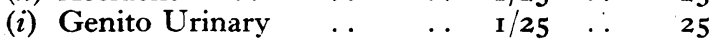

$\begin{array}{llllll}\text { (j) Ophthalmic } & \ldots & \ldots & 1 / 25 & \ldots & 25\end{array}$

$\begin{array}{lllllll}\text { (k) } \text { Skin } & \ldots & \ldots & \ldots & 1 / 25 & \ldots & 25\end{array}$

$\begin{array}{lllllll}\text { (l) T.B. } & \ldots & \ldots & \ldots & 2 / 25 & \ldots & 50\end{array}$

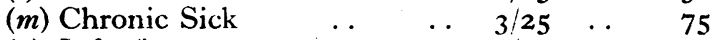

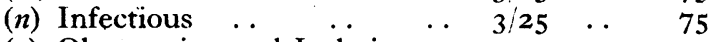

(o) Observation and Isolation .. 10 I0 ..

$\begin{array}{lllllll}\text { (p) Neurological } & \ldots & \ldots & 1 & 25 & \ldots & 25\end{array}$

I, OIO

Up to this point no serious problem arises, but once having determined the total bedcapacity and the various categories, the next most important point is the size and composition of the individual ward unit controlled by a Sister. The above schedule presupposes a unit of 25 beds and here is an opportunity to make some comparisons with our continental friends, who, no doubt after much consideration, are advocating the small wards or rooms. These small rooms are designed to hold only six beds as a maximum, with a ward unit varying between 25 and 50 beds, and in one case up to as many as 94 beds as a unit. This is quite contrary to the principles which have governed the planning of hospitals in this country for many years past, where the large pavilion type of ward, holding anything from 20 to 30 beds or more, with a few single bed wards attached, has been the universal practice. It is generally admitted that the small ward unit must increase the nursing difficulties, probably increases the size of the building and so will increase the cost, but, on the other hand it is urged that it provides greater privacy for the individual patient and so gives a more homely atmosphere. It must be remembered that in the two great hospitals in Stockholm, the ratio of nurses to patients is something like one nurse to four patients, where the ratio in this country is approximately one nurse to one patient, but in spite of this difference in ratio, the Swedish hospitals do not, appar ently, find any difficulty, from the nursing point of view, in dealing with a number of small wards strung out along the ward corridor.

Clearly it is not the function of the architect to decide the size of the wards, but a definite lead must be given by the medical and nursing authorities as to which of these principles is to be adopted, as the planning of the ward unit as a whole will be entirely different.

The writer has in mind something of a compromise, that is, a unit of 25 beds as representing a Sisters' unit, having a 20-bed ward capable of being easily divided into two ro-bed wards, which could be used for either sex if required, with every bed cubicled by curtains; there would be attached to the unit five single-bed wards, again capable of being used by either sex if necessary. By planning in this way, considerable flexibility can be obtained.

This unit, however planned, will carry with it a full complement of ancillary rooms, including all the additional rooms for sterilizing, dressings, etc., asked for by the General Nursing Council. As to the type of ward, 
whether it should be a pavilion, alcove or small ward, it is largely a matter of space available and no hard and fast rules should be laid down, but rather it should be left to discussion between the hospital authorities and their architect.

As a general guide, it is thought that the pavilion-type ward (where the beds are at right angles to the external walls) is likely to be better for teaching hospitals, as each bed can be isolated by curtains and approached easily from the centre of the ward, whereas in the alcove-type ward (where the beds run parallel with the external walls), they are in groups of four or six with glass partitions; the beds can be curtained, but the approach to the beds nearest to the external wall must be past the outer beds and is therefore not so convenient.

When considering the planning as a whole, the ideal is to produce a reasonably uniform ward unit, insofar as the external wall layout is concerned, which will enable the various units to be planned over each other, at the same time giving as much flexibility as possible in the internal planning of each individual unit. Here it may be pointed out that from time to time it has been suggested that hospitals should be so designed and built that they could be pulled down and rebuilt after a period of 25 years. How hospital architects would welcome this! But this is a completely wrong approach to an already difficult problem, as the building of a modern hospital is so complex in its planning and construction and its detail and equipment so costly, that it is inconceivable that a building (almost to be considered as temporary) could be built and satisfy the many needs of medical and nursing science and then, that it should be destroyed at the end of 25 years. Neither the State nor anyone else could contemplate such a suggestion. No, modern hospitals call for permanent buildings, but they must be planned and built so that, within limits, they can be altered, adapted and extended as future needs may require.

The writer suggests that one method is to construct them with floors of sufficient strength that (leaving external walls untouched) brick walls can be built anywhere at any time internally, which would mean that the whole of the original interior partitions could be demolished and the floor or floors replanned as required in the future.

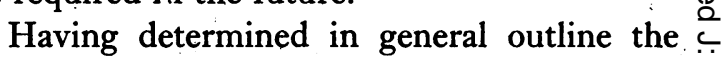
size and capacity of the inpatients' accom- $\Rightarrow$ modation, the problem is to find a 'shape' that will fit the site, with due regard to aspect, and one which will place the various ward units in their correct positions relative to each other and all other parts of the hospital. Here it would be well to draw attention to important differences between the continental planning and ours, in connection with the designing of the wards and sanitary offices. The small wards previously referred to and advocated by the Swedes, Swiss and French are not cross-ventilated (except by mechanical means), whereas our larger wards (if these are to be the type adopted) must be cross-ventilated, as we are not (perhaps wrongly) enamoured of mechanical ventilation for general wards. The desire to open windows when the ward wants ventilating is always present and remains one of our national characteristics. This applies especially in the case of sanitary offices where, in this country, by. law, all must have windows in external walls, whereas on the Continent, the offices can be and are plannes in all sorts of odd corners without light or air? and always with some form of mechanical air extract, but very rarely with mechanical input of fresh air. This simplifies planning, but it is doubtful whether it is really sound in principle.

It will be seen that to satisfy our conditions there must be radical differences in planning, as compared with the continental hospitals.

Again the question of concentration of movement must be considered throughout the planning; everything that can be done to reduce movement of staff and patients is essential. This is a point against the continental hospitals where their plans produce very long main and connecting corridors, some being over $\mathrm{I}, 000 \mathrm{ft}$. long.

It is clear that in a building to house as many as $\mathrm{I}, 000$ beds with all the ancillaries, it is impossible to have everything that is wanted so close together that movement is entirely eliminated, but it is thought that by planning round or from central towers, in which will be concentrated all vertical movement, the neces- 
sary lengths of corridor connecting the various units can be reduced to the minimum.

The diagram block plans, all approximately to the same scale, illustrating this article show a variety of possible layouts, varying, as they must, according to the shapes of the sites. No. $I$ and No. 2 are the plans of the Karoline and the Southern in Stockholm. (No site plans are available.) The other four are all suggestions for new hospitals to be built in this country; these four all show attempts to reduce the movement of staff and patients. If these four plans are compared with Nos. I and 2 it will be seen that, with staircase towers strategically placed, movement can be reduced. It is certain that the planning of all these new hospitals must be on a vertical rather than a horizontal basis, not only to reduce the long corridors but also to satisfy the prevailing town and country planning regulations regarding site cover and angles of light, and on the assumption that by agreement with the authorities the necessary additional height will be accepted to allow the full accommodation to be provided.

Perhaps the next important unit to consider is the operating theatre suite. It is assumed that for a I,000-bed hospital not less than six general theatres and probably two specialist theatres would be required and it may be that there would be two more, one for maternity and one for gynaecological cases. It is generally agreed that the theatres should be concentrated in one unit rather than the alternative of having individual theatres on different floors, with the possible exception of the two special theatres just referred to, which might well be planned in their own units. The concentration on one floor makes for economy in planning and in the servicing, not only for nursing staff but also for the costly equipment. The best position for the theatres is at the top of the building, with access from all main wards ; the highest level is chosen in order to obtain the best light and air and the added quietness away from the bustle of ward work. A full range of accommodation must be provided, with facilities for X-ray work and possibly a laboratory for pathological work, and it is as well to have some spare rooms in the suite for future and unknown uses, as it is always difficult to extend such a highly developed unit. Also it should be made clear from the beginning exactly what organization is to be planned for to satisfy the requirements of the surgeons and others using this unit. In the past the layout has often been determined to satisfy an individual surgeon, whereas it should be planned so that any surgeon using the unit will find what he wants.

In view of the possible use of the district hospitals as post graduate teaching centres, it may be desirable to have galleries to the theatres, but this is a matter for discussion when the plans are being drawn up.

With regard to the next important department, the central kitchens, it would seem that the basement is likely to be the most satisfactory position, and if comparisons are made with the continental hospitals where some have the kitchens at the lower level, as at the Karoline, or on the top floor, as at the Southern in Stockholm, no definite views are indicated as to which is considered the better.

The writer, who has had the privilege of seeing both the above hospitals, inclines to the view that the basement is the more satisfactory position, as there is no problem with regard to the taking in of stores and their subsequent delivery wherever required, whereas if the kitchens are on the top, all stores must, of necessity, be taken in at basement level and either stored at that level or taken to the top and used or stored there, which will mean much duplication of checking and storage space. There is also the problem of the removal of refuse, which is more easily dealt with at the lower levels. Clearly the answer to this problem is an efficient lift service, earmarked from the outset for kitchen service only, and this can be more satisfactorily done from the basement level than elsewhere. With such a lift service it should be possible to give quick and direct access to the main wards, dining rooms, etc.

There remains one further problem in connection with the kitchens and that is whether there should be a separate kitchen for the nurses' home. Much depends on the position of the home on the site; if no kitchen is required, then all the various dining rooms must be concentrated in the main hospital buildings and near enough to the central kitchen for quick service. This may lead to 


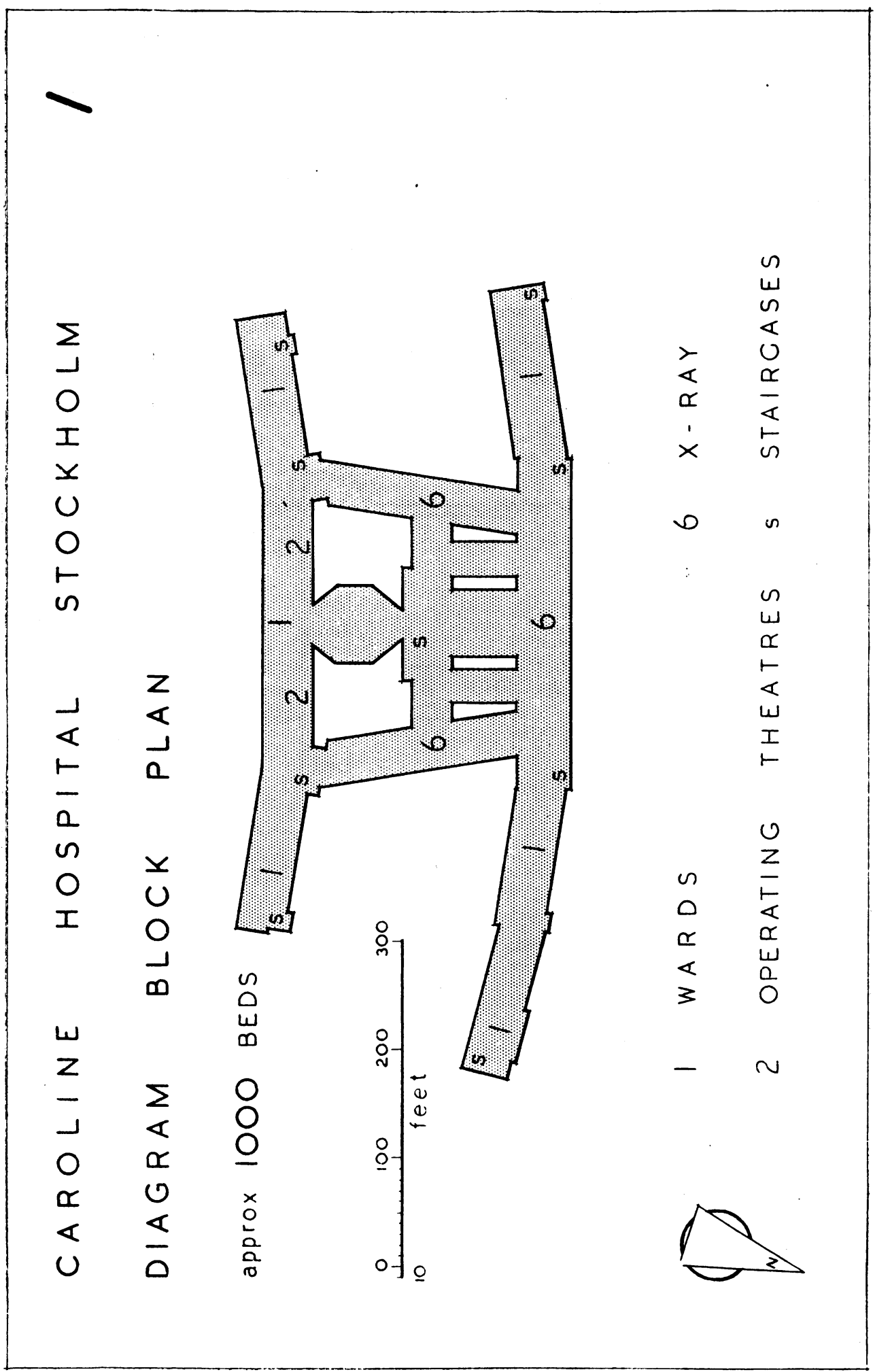




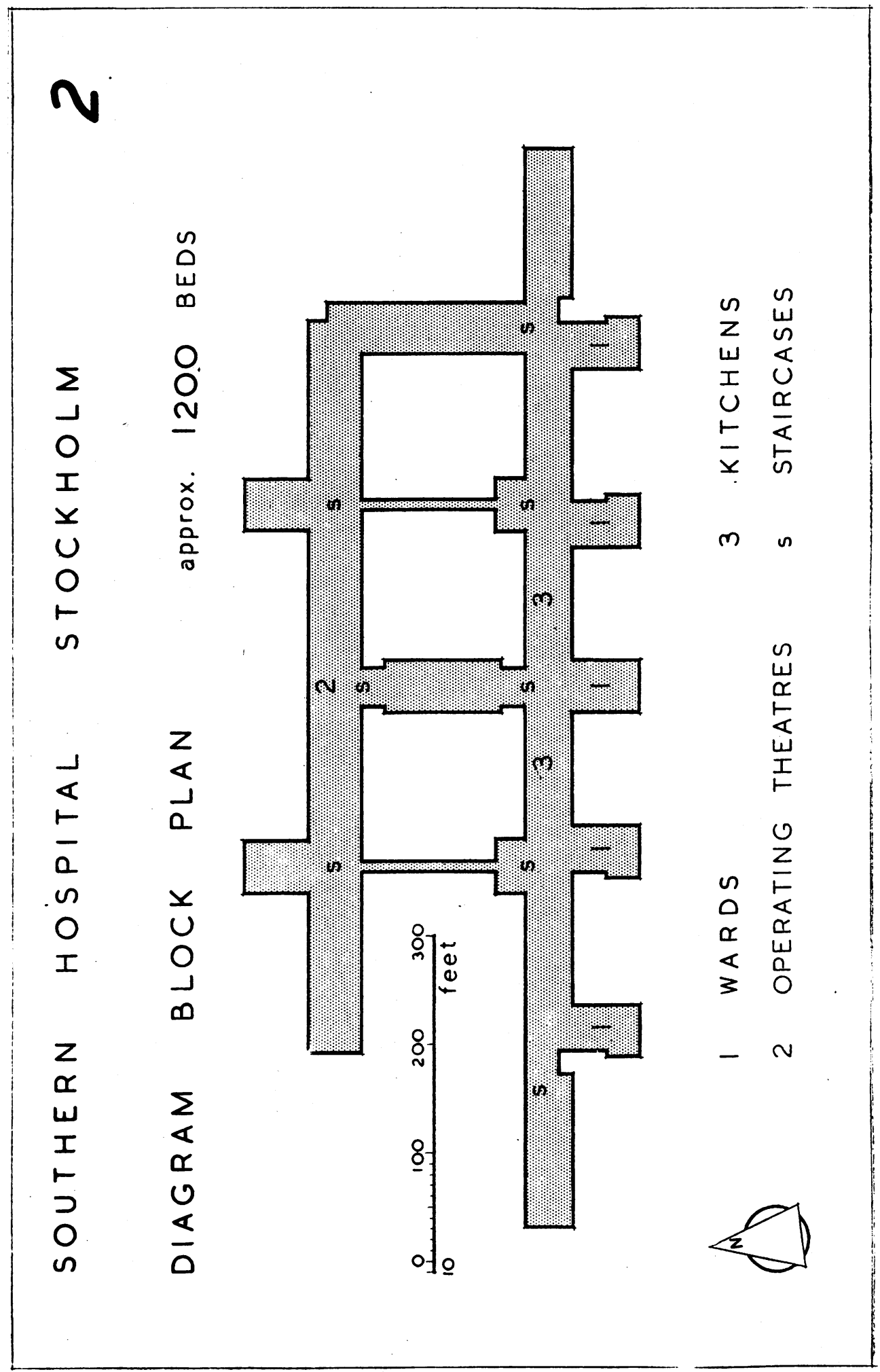




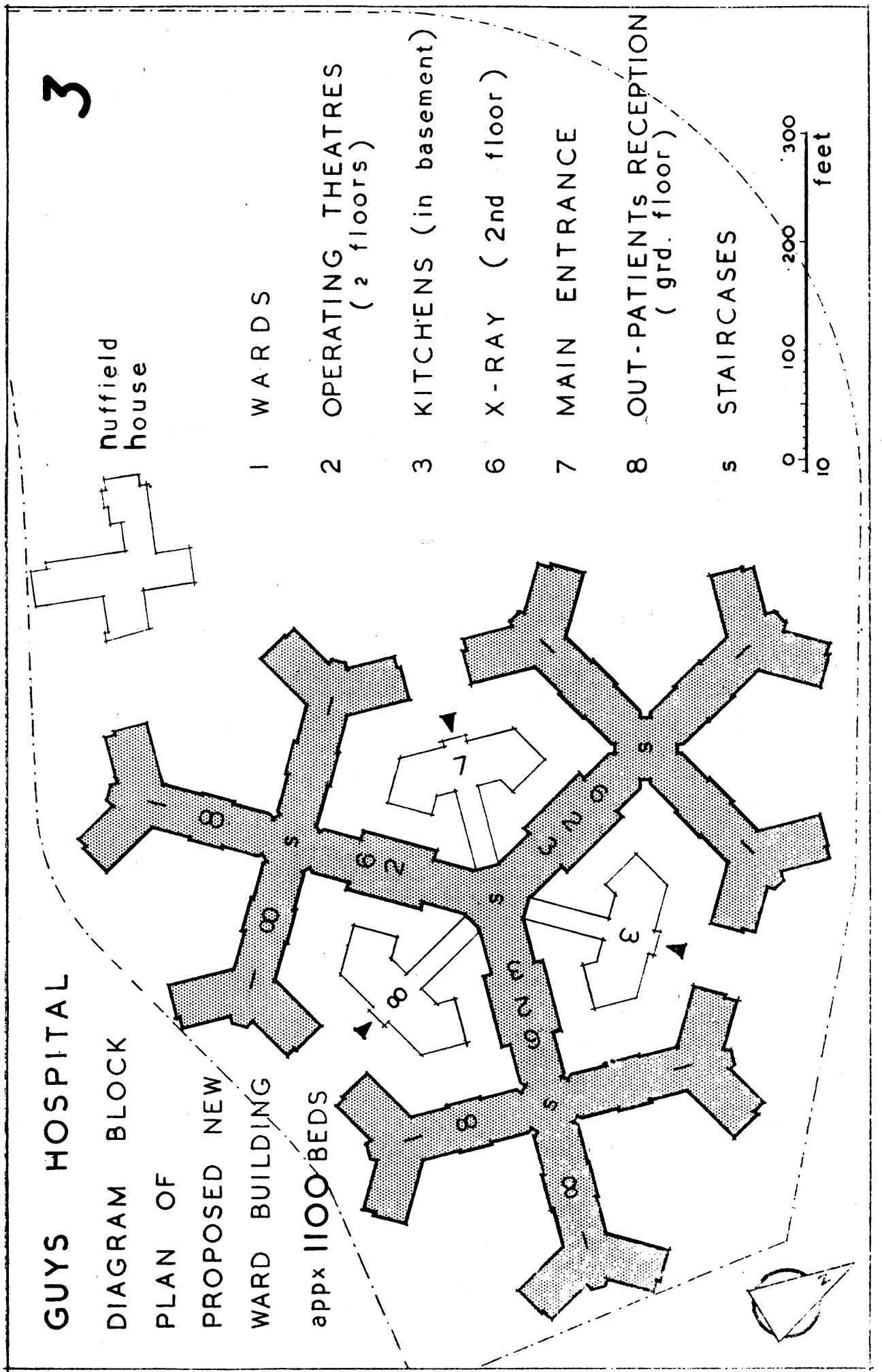




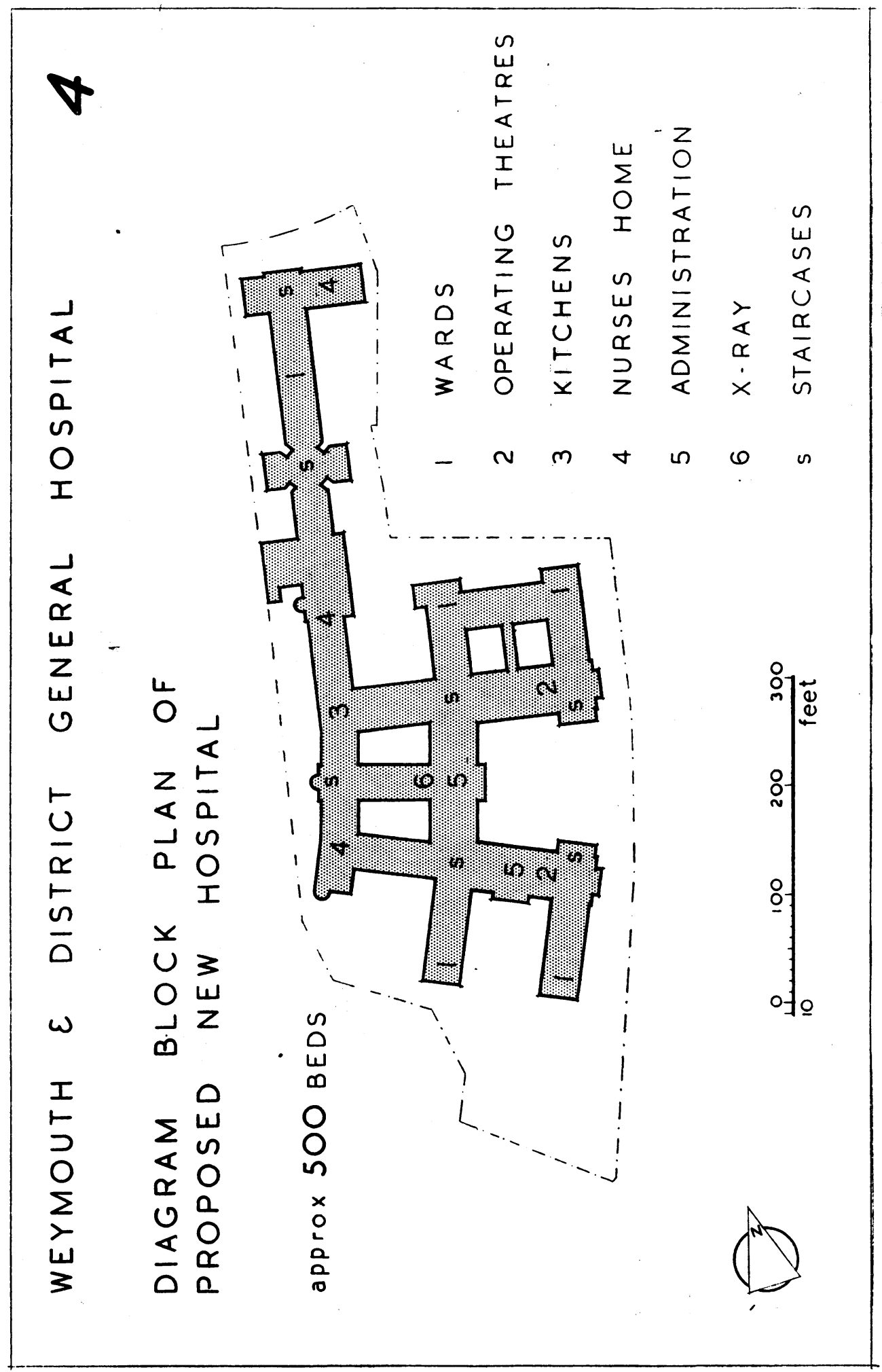




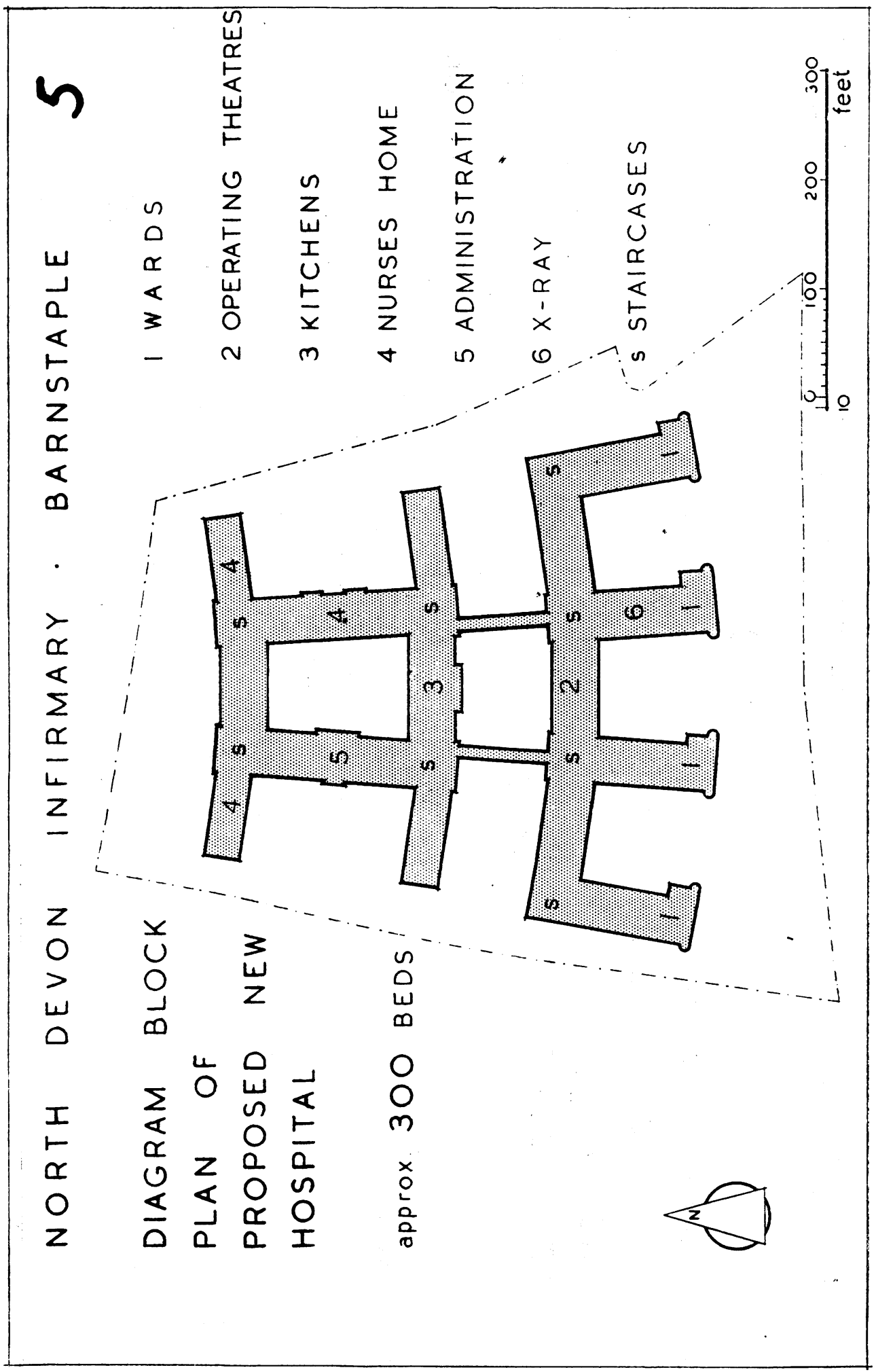




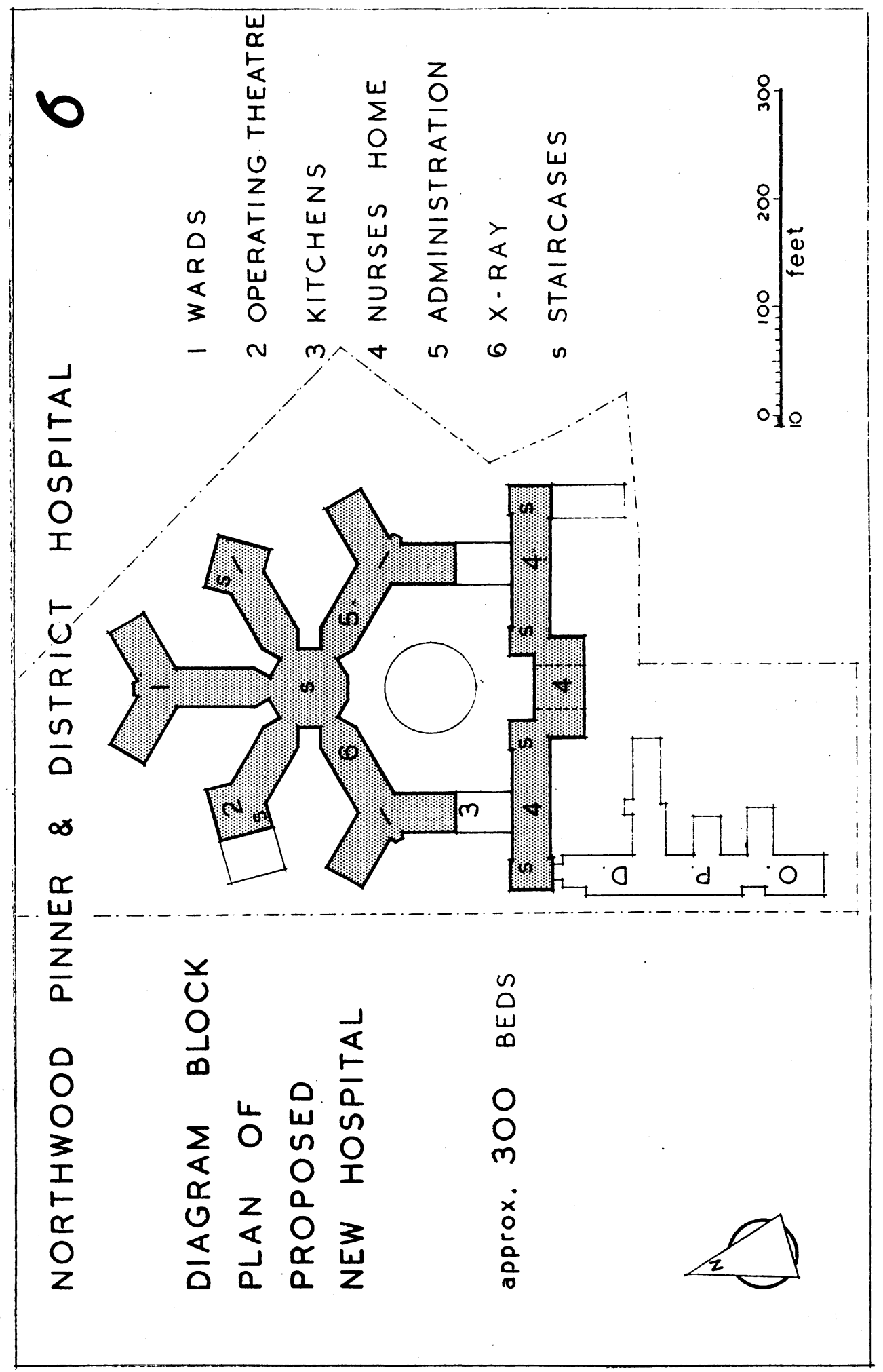

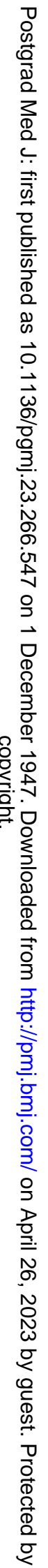


difficulties of planning and it means also that the central kitchen will be very large as it may have to deal with 2,000 or more people. At the same time it is clear that by concentration there will be a saving in staff and equipment and therefore in cost.

Probably the next most important group of departments to be considered are the various clinics forming the outpatients' department. In connection with this unit there is now the added problem of the health centre, dealing with maternity and child welfare, T.B. and V.D. cases, which unit it is thought could well be included in the general scheme but planned as a self-contained block. The main outpatients' department will contain a full range of accommodation for all specialists' work, and the positioning of the clinics, not only in relation to each other but also to the main wards, is most important. The old-fashioned idea of a large one-storey building, generally placed at one end of a long corridor and divorced from the main wards and other departments, seems all wrong today and it is thought that, as at the Karoline in Stockholm, the ideal way is to plan the main specialist clinics as near their corresponding ward units as possible. The alternative method of having the specialist clinics actually on the same floor as the corresponding ward unit and controlled by the ward Sister does not seem to the writer to be good or likely to be satisfactory, as it would overload the Sister and would bring outpatients into very close touch with the inpatients and the routine work of the ward.

Among the clinics, probably the most important is the radiodiagnostic department, today the most technical of all the units in the hospital. The unit at the Karoline, Stockholm, is a masterpiece of planning and equipment and is designed on a very large scale with ample room to move and expand. The layout and apparatus are magnificent and, placed as it is in the centre and at first-floor level, between in- and outpatients, its position is idea!.

To plan on this scale may not be so necessary in the type of hospital under discussion, but it is clear that the positioning, planning and equipping of the unit must be given the utmost care and consideration.

As to its position in the plan, in view of the fact that it has to serve both in- and outpatients' departments with perhaps more work in the latter, it is essential that it should be near the centre of things, easily accessible from all parts of the hospital. It should possibly be round about the centre vertically, which may bring it to the first or second floors. Wherever it may finally be put there must be good light and air for all rooms. Its detailed planning must be a matter of the closest collaboration between the radiologist in charge and the architect and there should be discussions between them from the very beginning. Space should always be left available in the unit for extensions and modifications to allow for the changes in plant and technique which are bound to occur in the future.

With regard to equipment, this is so much a matter for experts that the architect can but carry out his instructions to provide what will be wanted in the way of space and amenities.

Many other departments, all important, will be included in the general layout; administrative, secretarial, medical and other offices must be provided. Also offices for the Matron, Assistant Matron, Steward and so on, all to be found their right place in the scheme.

Again the positioning and planning of the central power house is of great importance and this unit can be likened to the heart, as being the one department which must be big enough for its job and one which can never be allowed to go wrong, for if it does the whole hospital must cease to function.

Enough has been said to give an idea of the approach to the planning of a future district hospital, without, it is hoped, too much technical detail and no attempt has been made to describe any particular department, as this would entail much discussion on specific detail and is considered outside the scope of this article.

To sum up, therefore, it is clear that first and foremost is the question of site, its size, shape and suitability; secondly, the final decision as to bed capacity and its various sub-divisions; thirdly, the planning of the ward units-and here once more a word of warning - that it is certain that under modern requirements, and having in mind all the different conditions which have to be satisfied, 
no form of stereotyped plan out of a pigeonhole can ever be successful, in fact, such an idea is the very negation of planning, as it would stultify all thought and progress in design, construction and equipment, now and in the future. Fourthly, the importance of placing the wards and the various specialist departments, including the nurses' and maids' home and their departments, on the site in the correct relation, to each other and all other̃ departments.

And, finally, the necessity for the closes踝 liaison between the hospital authorities, theiradministrative staffs, and both medical and nursing staffs and their architect, from the very beginning until the day when the building is complete in all its detail, occupied by patients and handed over to the State.

\section{LAY CLINICIANS}

No. 7

Often when reading a book or play one comes across an excellent description of some disease, which though written by a layman, is probably more happily phrased than any doctor could achieve. We hope to introduce some of these 'case records' in subsequent issues and for those who would like to try their hand at naming the author and book this information will be given at the end of the extract.

\section{SECOND YEAR OF THE WAR}

\section{The Plague of Athens}

\section{B.C. 430}

It first began, it is said, in the parts of Ethiopia above Egypt, and thence descended into Egypt and Libya and into most of the King's country. Suddenly falling upon Athens it first attacked the population in Piraeuswhich was the occasion of their saying that the Peloponnesians had poisoned the reservoirs, there being as yet no wells there-and afterwards appeared in the upper city, when the deaths became much more frequent. All speculation as to its origin and its causes, if causes can be found adequate to produce so great a disturbance, I leave to other writers, whether lay or professional; for myself, I shall simply set down its nature, and explain $\frac{\mathbb{\infty}}{3}$ the symptoms by which perhaps it may de recognised by the student, if it should evero break out again. This I can the better do, I had the disease myself, and watched operation in the case of others.

That year then is admitted to have been⿳亠口冋 otherwise unprecedently free from sickness and such few cases as occurred all determined in this. As a rule, however, there was no ostensible cause; but people in good health ${ }^{3}$ were all of a sudden attacked by violent heats in the head, and redness and inflammation in the eyes, the inward parts, such as the throas and tongue, become bloody and emitting ari unnatural and fetid breath. These symptoms. were followed by sneezing and hoarseness? after which the pain soon reached the chest, and produced a hard cough. When it fixed in the stomach, it upset it ; and discharge of bile of every kind named by physicians en sued, accompanied by very great depression $N$ In most cases also an ineffectual retching fol त lowed, producing violent spasms, which in some cases ceased soon after, in others much later. Externally the body was not very hoto to the touch, nor pale in its appearance, but్ reddish, livid, and broken out into smalf pustules and ulcers. But internally it burned 